\title{
Effects of genetic immunization of Swiss outbred mice with human thyroid stimulating hormone receptor cDNA plasmids harboring gain-of-function mutations
}

\author{
Su-Chin Ho, Sui-Sin Goh ${ }^{1}$, Irene H C Kee ${ }^{2}$, Pierce K H Chow ${ }^{2}$, Chin-Pin Yeo ${ }^{3}$ \\ and Daphne H C Khoo' \\ SingHealth Research Facilities, Singapore Health Service, 5, Hospital Drive, Block A, \#03-04, Singapore 169609, Republic of Singapore \\ Departments of ${ }^{1}$ Endocrinology, ${ }^{2}$ Experimental Surgery and ${ }^{3}$ Pathology, Singapore General Hospital, Outram Road, Singapore 169608, Republic of Singapore \\ (Requests for offprints should be addressed to S-C Ho; Email: ho.su.chin@sgh.com.sg)
}

\begin{abstract}
Animal models of Graves' disease have been generated in recent years with various vaccination protocols using wild-type TSH receptor. In this study, we report the findings of genetic immunization of Swiss outbred mice with three different mutated human $\mathrm{TSH}$ receptor plasmids, each containing one constitutive activating mutation located at the ectodomain $(\mathrm{S} 281 \mathrm{~N})$, exoloop $(\mathrm{I} 486 \mathrm{~F})$, and transmembrane segment $(\mathrm{D} 633 \mathrm{H})$ respectively. Although the overall rate of thyrotoxicosis in the mice was $<10 \%$, anti-TSH receptor antibodies could be detected in many animals by flow cytometry, radioreceptor assay, and functional bioassays using recombinant human TSH receptor. Mice injected with plasmids harboring activated mutants ( $\mathrm{S} 281 \mathrm{~N}$ and $\mathrm{D} 633 \mathrm{H}$ ) showed production of predominantly stimulating antibodies, whilst those treated with wild-type receptor plasmids generated mainly blocking sera. Most of these antibodies displaced radiolabeled bovine TSH, and their epitopes, independent of functional characteristics, were mapped to the first 271 amino acids of the TSH receptor. This supports recent findings that binding of stimulatory or blocking antibodies lie in close proximity within the leucine-rich repeat region.
\end{abstract}

Journal of Molecular Endocrinology (2007) 38, 277-288

\section{Introduction}

Graves' disease (GD) is an autoimmune thyroid disorder resulting from agonistic action of anti-thyroid stimulating hormone (TSH) receptor antibodies (TRAB) on the TSH receptors (TSHR), leading to thyroid hyperplasia and thyrotoxicosis (Weetman 2000, Davies et al. 2005). Only humans develop GD spontaneously and over the years, much effort has been directed towards the development of animal GD models that will serve as vital tools for understanding the disease pathogenesis of thyroid autoimmunity. Using novel immunization approaches, several groups have succeeded in inducing hyperthyroidism and thyroid stimulating antibodies (TSAB) in various mouse strains. These include in vivo expression of TSHR by injecting syngeneic cells coexpressing the TSHR, major histocompatibility complex (MHC) class II antigen, and a costimulatory molecule, or alternatively genetic immunizations using naked DNA plasmids or adenovirus vector encoding the TSHR (Shimojo et al. 1996, Costagliola et al. 1998a, 2000, Kaithamana et al. 1999, Nagayama et al. 2002, Nagayama 2005). These methods vary in the incidence of hyperthyroidism, prevalence of $\mathrm{TSAB}$, and intrathyroidal inflammatory infiltrates.
Various attempts have also been made to improve the rate of hyperthyroidism. One such study succeeded in inducing a high rate of hyperthyroidism by using adenovirus that expresses only the free A subunit of the TSHR instead of the full-length holoreceptor (Chen et al. 2003). Thus far, most studies have employed wildtype TSHR in their animal experimentation. Investigation into the effect of $\mathrm{Y} 601 \mathrm{H}$ polymorphism, a mutation that results in low constitutive cyclic AMP (cAMP) production, found no influence on the outcome of DNA vaccination in BALB/c mice (Pichurin et al. 2002). However, the reverse strategy, i.e. investigating the effects of activating TSHR mutations on induction of hyperthyroidism, has not been explored. We hypothesize that if constitutively active TSHR mutants are used in the immunization process, the mutants that are synthesized and expressed by the antigen-presenting cells (i.e. myocytes, Langerhan's cells, or dendritic cells) may potentially affect endosomal processing into peptides, thereby exposing novel epitopes that may be important in receptor activation and otherwise absent in wild-type receptor. This process can potentially result in the formation of a repertoire of antibodies that is different from immunization with wild-type receptor and hence affect the rate of GD 
induction. In this study, we immunized 45 Swiss outbred mice with plasmids encoding the cDNA of three constitutively active TSHR mutants, each harboring a mutation located at codon $281(\mathrm{~S} 281 \mathrm{~N})$ in the ectodomain, codon 486 (I486F) in the first exoloop, and codon $633(\mathrm{D} 633 \mathrm{H})$ in the sixth transmembrane segment of the TSHR. They are spontaneous mutations which have been identified in toxic multinodular goiter, autonomous functioning thyroid adenomas/cancer, and famililial non-autoimmune hyperthyroidism (Parma et al. 1995, 1997, Russo et al. 1996, 1997, Duprez et al. 1997, Kopp et al. 1997, Gruters et al. 1998, Tonacchera et al. 1998, Camacho et al. 2000). These single amino acid alterations have been known to cause structural and conformational changes in the protein that are important in constitutive receptor activation in the absence of its ligand TSH. We tested our hypothesis and found that, indeed, the prevalence of TSAB was higher in mice immunized with activating TSHR mutants compared with those injected with wild-type receptor.

\section{Materials and methods}

\section{Animal experimentation}

DNA vaccination was performed as previously described by Costagliola et al. (2000) with minor modifications. A total of 45 female Swiss outbred mice, aged 6- to 8-weeks-old, were used. All animals were pretreated with $100 \mu \mathrm{l}$ cardiotoxin $(10 \mathrm{mM}$, purified from the venom of Naja nigricollis; Calbiochem, La Jolla, CA, USA) by i.m. injection at the anterior tibialis muscles. Control mice $(n=5)$ received $100 \mu \mathrm{g}$ of the empty vector pCDNA3 at the same site, 5 days later, while study mice were each vaccinated with $100 \mu \mathrm{g}$ DNA containing either (1) wildtype TSHR $(n=10)$, (2) S281N TSHR $(n=10)$, (3) I486F TSHR $(n=10)$, or (4) D633H TSHR $(n=10)$. DNA injections were repeated at week 4 and 8 and the animals were killed at week 16 by chloroform inhalation. Blood was collected by intra-cardiac puncture and sera used for subsequent study. The mice were housed under pathogen-free conditions and fed standard chow at the Department of Experimental Surgery, Singapore General Hospital. Weights of the animals were monitored at each injection and at death. The study adhered to IACUC guidelines and was approved by the local IACUC committee.

\section{Serological parameters}

\section{Total T4}

Total T4 levels were measured by Vitros ECi Immunodiagnostic System (Ortho-Clinical Diagnostics, Rochester NY, USA).

\section{Flow cytometry using TSHR expressing cells}

Flow cytometry was performed as described previously using $5 \mu \mathrm{l}$ mouse sera in a $100 \mu \mathrm{l}$ reaction and results were expressed in arbitrary fluorescence units (FU) (Ho et al. 2001, 2005). The cell lines used in this study were: (i) JP19, which expressed wild-type full-length TSHR, (ii) GT14, which expressed only the ectodomain of the TSHR anchored on a glycophosphatidylinositol insert (ECD-GPI) (Ludgate et al. 1992, Costagliola et al. 1998b), and (iii) TLT, which expressed a chimera TSHR-LH receptor (LHR) ectodomain on a GPI anchor. Construction of this chimera is described below.

\section{TSH-binding inhibitory immunoglobulin (TBII)}

JP19 cells plated at a density of 30000 cells per well were incubated for $4 \mathrm{~h}$ with $100 \mu \mathrm{l}$ binding assay buffer (NaCl-free HBSS containing $277 \mathrm{mM}$ sucrose, 5\% BSA, and $25 \mathrm{mM}$ HEPES, pH 7.4) containing 30000 c.p.m. ${ }^{125}$ I-labeled bovine TSH (bTSH) and $5 \mu \mathrm{l}$ serum. Cells were washed twice with cold buffer and incubated with $100 \mu \mathrm{l} 1 \mathrm{M} \mathrm{NaOH}$ for another $15 \mathrm{~min}$ before counting, as described previously (Ho et al. 2001, 2005). Experiments were performed in triplicate for each serum sample and the intra-assay coefficient of variation for c.p.m. obtained was $5 \cdot 6 \%$. The TBII value of each sample was obtained using the formula: $(1-(\mathrm{TSH}$ binding in the presence of test serum/mean TSH binding in presence of control sera) $) \times 100$.

\section{Thyroid-stimulating antibody (TSAB) and thyroid-stimulating blocking antibody (TSBAB)}

For TSAB, $30000 \mathrm{JP} 19$ cells per well were incubated at $37^{\circ} \mathrm{C}$ for $4 \mathrm{~h}$ in the presence of $5 \mu \mathrm{l}$ mouse serum and $95 \mu \mathrm{l}$ buffer consisting of $124 \mathrm{mM} \mathrm{NaCl}, 5 \mathrm{mM} \mathrm{KCl}$, $1.25 \mathrm{mM} \mathrm{KH}_{2} \mathrm{PO}_{4}, 1.25 \mathrm{mM} \mathrm{MgSO}, 1.45 \mathrm{mM} \mathrm{CaCl}$, $8 \mathrm{mM}$ glucose, $25 \mathrm{mM}$ Rolipram (Sigma Aldrich Corp.), $25 \mathrm{mM}$ HEPES, and $0 \cdot 05 \% \mathrm{BSA}$ at $\mathrm{pH} 7 \cdot 4$. Cyclic AMP released into the supernatant was collected and measured by RIA kits (NEN TM, Boston, MA, USA). Experiments were done in triplicate for each mouse serum and the results were expressed as $\mathrm{pmol} / \mathrm{ml}$. For TSBAB assay, the same procedure was performed with the addition of $200 \mu \mathrm{IU} / \mathrm{ml} \mathrm{bTSH}$ and the sample result was also expressed in $\mathrm{pmol} / \mathrm{ml}$. The intra-assay coefficients of variation of cAMP obtained for TSAB and TSBAB were $10 \cdot 8$ and $12 \cdot 8 \%$ respectively.

\section{Preparation of plasmids for injection}

Activating mutations, S281N, I486F, and D633H were introduced into the wild-type full-length human TSHR in pCDNA3 by PCR using the following primers: 
281-Forward(F) CTCACACGGGGTGACCTTTCTTACCCAAATCACTGCTGTGC

281-Reverse(R) GGGTAAGAAAGGTCAGCCCGTGTGAGGTGAAGGAAACTCAAGG

486-F ACTCACTCTGAGTACTACAACCATGCCTTTGACTGGCAG

486-R GGTTGTAGTACTCAGAGTGAGTGTAGAGGTCTACAGAGGC

633-F CCAAGAGGATGGCTGTGTTGATCTTCACCCACTTCATATGC

633-R CAACACAGCCATCCTCTTGGCAATTTTGGTATCTTTGTC

Each pair of primers, complementary to the opposite strands, was extended with Pfu DNA Polymerase (Promega, Madison, WI, USA) according to the manufacturer's protocol using the following conditions: initial denaturation at $95{ }^{\circ} \mathrm{C}$ for $30 \mathrm{~s}$ for one cycle, followed by denaturation at $95^{\circ} \mathrm{C}$ for $30 \mathrm{~s}$, annealing at $55^{\circ} \mathrm{C}$ for $1 \mathrm{~min}$, extension at $72^{\circ} \mathrm{C}$ for $14 \mathrm{~min}$ for 15 cycles, and final extension at $72^{\circ} \mathrm{C}$ for $4 \mathrm{~min}$. The PCR product was digested overnight with Dpn1 (New England Biolabs, MA, USA) and followed by transformation in competent Escherichia coli. Colonies were picked and DNA was extracted using QIAprep Miniprep kit (QIAGEN GmbH, Germany) followed by Big Dye sequencing (Applied Biosystems, CA, USA) for detection of mutations. Constructs harboring the three desired mutations were then digested with Xhol and Xbal and the fragments ligated into the vector pCDNA3. Larger-scale plasmid preparations for injections were done with Maxiprep kit (QIAGEN GmbH, Germany) and the DNA pellet dissolved in PBS.

\section{Construction of stable cell lines expressing TSHR-LHR chimera}

Two chimera constructs, TLT and LTT in pSVL, containing segments of LHR in the ectodomain of full-length TSHR were reported previously and kindly given by Dr S Costagliola (Costagliola et al. 2002a,b). In brief, TLT contains TSHR sequences from amino acids 1-271 followed by homologous LHR sequences from codon 272 to the CEDIM motif located at the insertion into the cell membrane. LTT, on the other hand, contains LHR sequences from amino acids 1-271 followed by TSHR sequences from codon 272 onwards right up to the CEDIM motif. The ectodomains of TLT and LTT were excised by restriction enzymes Xhol and EcoRV and transferred into similarly cut TSHR ECDGPI in pCDNA3 vector. TLT and LTT ectodomains anchored on GPI thus created were subsequently lifted out by Xbal and Kpn1 digestion and cloned into pEFIN as followed: TSHR ECD-GPI in pEFIN vector was first thoroughly cut with Xbal, followed by brief digestion with Kpn1 to allow the harvest of a $5.9 \mathrm{~kb}$ fragment bearing the correct ends to allow the insertion of TLT and LTL ectodomains. The final products were verified by direct sequencing. For construction of stable cell lines expressing the LHR-TSHR chimeras, $2 \mu \mathrm{g}$ DNA were used for transfection of $200000 \mathrm{CHO}$ cells with Geneporter (Gene Therapy Systems Inc., CA, USA) followed by the addition of Geneticin G418 (Gibco Invitrogen Corp., CA, USA) at $48 \mathrm{~h}$ for selection. Cells were then detached, divided, and plated in smaller quantities to make a few cell lines. The surface expression of chimera proteins in these lines were assessed by flow cytometry using two mouse monoclonal antibodies IRISAb1 and 15.2 (both kind gifts from Dr S Costagliola). IRI-SAb1, whose linear epitope is located in the first 280 residues of the ECD, was used for assessing TLT lines, while $15 \cdot 2$, whose linear epitope is located close to the C-terminal portion of the ECD from amino acid residue 371-400 immediately upstream of the first transmembrane helix, was used for LTT lines (Costagliola et al. 2002a,b). The LTT chimera was poorly expressed at cell surface and was sequestrated intracellularly (stable transfection repeated twice; data not shown). The TLT construct, on the other hand, showed good cell-surface expression and one cell line with the highest level of receptor protein was selected for subsequent experiments.

\section{Statistical analyses}

Data were analyzed and graphs plotted using SPSS 9.0 software. Non-parametric data were expressed as medians and inter-quartile ranges (IR 25-75\%). In the determination of serum performance on various assays, mean values of controls were first calculated and cut-off set arbitrarily at 2 s.D. from the mean. Fisher's exact test was used to determine the significance of differences between the number of mice positive or negative for a parameter in a particular group. Differences in the magnitude of responses between groups of mice were evaluated for significance using Mann-Whitney $U$-test. Correlations between parameters were calculated by Spearman coefficient. A $P$ value of $<0.05$ was taken as statistically significant.

\section{Results}

All the 45 mice completed the entire immunization protocol without mortality.

\section{Weight}

The weights of animals in the various treatment groups did not differ significantly from control either before or after the immunization (before: control $24 \cdot 4 \mathrm{~g}(23 \cdot 5-26 \cdot 7)$, wild type $24.5 \mathrm{~g}(23 \cdot 6-26 \cdot 3)$, S281N $24 \cdot 9 \mathrm{~g}(22 \cdot 0-26 \cdot 2)$, 
I486F $23.9 \mathrm{~g}(22 \cdot 2-26 \cdot 2)$, D633H $23.9 \mathrm{~g} \quad(22 \cdot 2-26 \cdot 5)$ and after: control $33.9 \mathrm{~g}(32 \cdot 8-50 \cdot 1)$, wild type $40.0 \mathrm{~g}$ $(34 \cdot 3-47 \cdot 8)$, S281N $37 \cdot 7 \mathrm{~g}(33 \cdot 1-43 \cdot 0)$, I $486 \mathrm{~F} 34 \cdot 1 \mathrm{~g}$ $(31 \cdot 9-38 \cdot 2)$, D633H $39 \cdot 4 \mathrm{~g}(33 \cdot 0-43 \cdot 2))$. All animals gained a significant amount of weight during the immunization period $(P<0 \cdot 001)$.

\section{Total T4}

The median total T4 levels at death for treatment groups did not differ significantly from those of controls (control $60 \cdot 2 \mathrm{nmol} / 1(55 \cdot 6-87 \cdot 3)$, wild type $63 \cdot 8 \mathrm{nmol} / 1$ $(55 \cdot 9-79 \cdot 4)$, S281N $72 \cdot 0 \mathrm{nmol} / 1 \quad(63 \cdot 0-94 \cdot 7), \mathrm{I} 486 \mathrm{~F}$ $65 \cdot 3 \mathrm{nmol} / 1$ (49.2-76.0), and D633H $67 \cdot 4 \mathrm{nmol} / 1$ $(52 \cdot 6-80 \cdot 9))$. For the mice injected with wild type, I486F, and D633H TSHRs, only 1 out of 10 mice in each group showed elevated total T4. No thyrotoxicosis was found in mice immunized with S281N TSHR. There was no statistical significant difference in the rates of thyrotoxicosis amongst groups.

\section{TBII}

Wild-type and D633H TSHR-vaccinated mice were 90\% positive for TBII activity, while S281N and I486F TSHR injected groups were both positive for TBII in $50 \%$ of cases. This difference was not significant. However, TBII-positive cases in S281N and I486F TSHR groups generally had much lower TSH displacing ability when compared with the wild-type TSHR group. Their median TBII values were also significantly lower when compared with the wild-type TSHR group (wild type: $25 \cdot 6 \%(14 \cdot 5-52 \cdot 1)$; S281N: $6 \cdot 7 \%(2 \cdot 8-9 \cdot 1), P=0 \cdot 007$; I486F: 5·7\% (3·2-8·0), $P=0 \cdot 002$; Fig. 1$)$.

\section{$T S A B$}

Immunization with wild-type TSHR generated only two sera positive for TSAB (20\%), while S281N, I486F, and D633H TSHR groups had 80, 50, and $90 \%$ positive cases respectively (Fig. 2). Differences in prevalence were significant for S281N and D633H TSHR injected groups when compared with wild-type receptor injection $(P=0.023$ and 0.005 respectively $)$. All the three mutant TSHR groups achieved significantly higher TSAB levels compared with those in wild-type receptor group (wild type: $1.25 \mathrm{pmol} / 1(0.88-1.92)$ vs S281N: $2.50 \mathrm{pmol} / 1$ $(2 \cdot 06-5 \cdot 00), P=0 \cdot 005$; I486F: $2 \cdot 15 \mathrm{pmol} / 1$ (1.72-2.90), $P=0 \cdot 013$; D633H: $3 \cdot 28 \mathrm{pmol} / 1(2 \cdot 67-3 \cdot 76), P=0 \cdot 001)$.

\section{TSBAB}

Wild-type TSHR injected mice developed the highest incidence of blocking antibody TSBAB $(50 \%)$, while the incidences in S281N and I486F TSHR injected groups were lower at 10 and $30 \%$ respectively (Fig. 3).
The difference was not significant. Of interest, none of the mice immunized with D633H TSHR tested positive for blocking bioactivity and this was significantly different compared with the wild-type TSHR group $(P=0 \cdot 033)$. The median TSBAB levels achieved with mutant receptor immunization also did not differ significantly from that of wild-type receptor injection. However, among the TSBAB-positive sera, those obtained from wild-type receptor vaccination showed clear suppression of TSH-mediated cAMP production, while those obtained from mutant injections tended to be only marginally positive.

\section{Flow cytometry}

Figure 4 shows the flow cytometry readings obtained using GT14 and JP19 cell lines from each individual serum with cut-off levels set at $13 \cdot 1$ and $10 \cdot 7 \mathrm{FU}$ respectively. There was concordance in TRAB detection among the 10 mice injected with wild-type TSHR: eight $(80 \%)$ were positive for TRAB on both cell lines, while the remaining two mice were negative on both cell lines. In contrast, TRAB from mutant receptor groups recognized holoreceptors on JP19 cells poorly. Detection rates were only 30,10 , and $20 \%$ positive in $\mathrm{S} 281 \mathrm{~N}$, I486F, and D633H TSHR groups respectively compared with $80 \%$ in the wild-type TSHR group and this decline was significant in the latter two $(P=0.005$ and 0.023 respectively). Flow cytometry performed with GT14 cells was a more efficient and sensitive method. Using these cells, the prevalence of positive sera rose for all the three mutant groups, especially for D633H TSHRinjected animals (S281N 50\%, I486F 40\%, and D633H $90 \%$ ) and their prevalence was comparable with that of wild-type group.

Ratios of FU obtained from GT14 to JP19 cells were calculated and used as a means of comparing antibody affinity between treatment groups. Data obtained from control mice were expectedly almost uniform 0.95 $(0 \cdot 80-1 \cdot 18)$, while mice injected with D633H TSHR had the highest ratio $(3 \cdot 50,2 \cdot 79-6.93)$ followed by wild-type TSHR $(2 \cdot 59,1 \cdot 44-2 \cdot 91)$, I486F TSHR $(1 \cdot 74$, $0 \cdot 94-2 \cdot 41)$, and S281N TSHR $(1 \cdot 67,0 \cdot 85-3 \cdot 34)$. Only the difference between wild-type TSHR and D633H TSHR groups reached statistical significance $(P=0 \cdot 035)$, indicating a preferential binding of antibodies for the ECD-GPI over the full-length receptor in the latter group of animals. Comparisons of $\mathrm{FU}$ ratios were also made between groups according to TSAB, TSBAB, and TBII status. GT14 to JP19 FU ratio were significantly lower for TSBAB- and TBIIpositive cases than negative cases (TSBAB: positive 1.44 $(1 \cdot 34-2 \cdot 11)$ vs negative $2 \cdot 81(1 \cdot 67-5 \cdot 08), P=0 \cdot 031$ and TBII: positive $1.39(0.93-2 \cdot 26)$ vs negative $2 \cdot 80(1.87-$ $4 \cdot 34), P=0 \cdot 017)$, indicating that antibodies with TSH displacement properties or blocking activities bound 

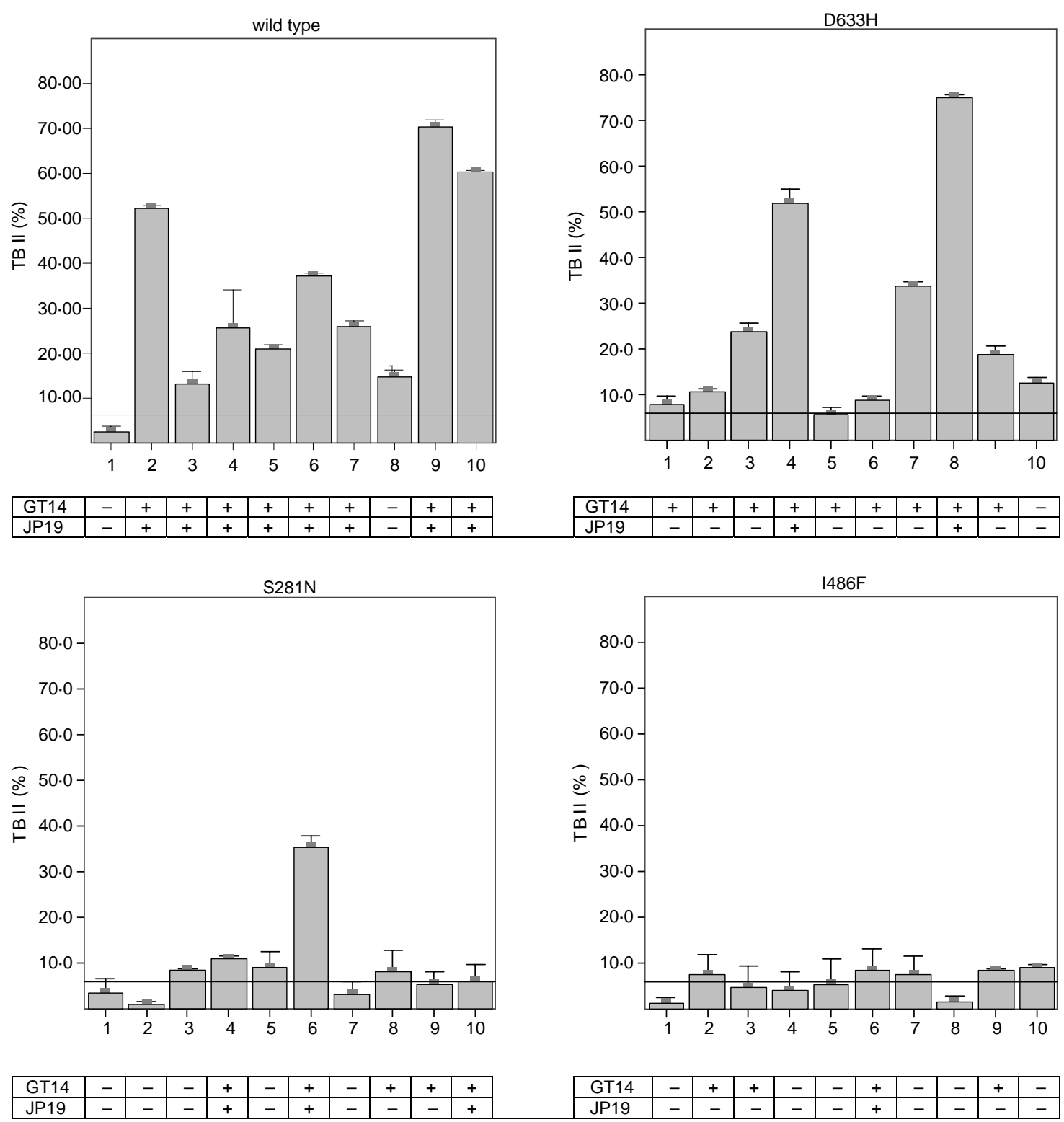

Figure 1 TBII activities of Swiss outbred mice immunized with wild-type, S281N, I486F, and D633H TSHRs. Each serum was assayed in triplicates. Bars represent mean of triplicate results and error bars represent S.E. of mean. Solid grid line represents cut-off for TBII assay set at $6 \cdot 1 \%$. Mean values above this cut-off are considered positive for the assay. Wild-type and D633H TSHR-injected groups achieved $90 \%$ prevalence, while S281N and I486F groups achieved 50\% prevalence (results not statistically significant). Note that wild-type TSHR group achieved significantly higher TBII activity levels when compared with S281N and I486F TSHR injected mice (wild-type: 25.6 (14.5$52 \cdot 1)$ vs S281N: $6 \cdot 7(2 \cdot 8-9 \cdot 1), P=0.007$ and I486F: 5.7 (3.2-8.0), $P=0.002)$. Tables below bar charts show individual serum's flow cytometry status performed with GT14 and JP19 cell lines: + and - denote positive and negative results respectively. Sera with strong TBII activities tended to be positive for both GT14 and JP19 flow cytometric assays. TBII values correlated significantly with GT14 ( $r=$ $0.74, P<0.0001)$ and JP19 $(r=0.57, P<0.001)$ FU readings.

JP19 holoreceptors to a larger extent. The ratios for TSAB positive and negative sera were both similar (positive $2 \cdot 47(1 \cdot 52-5 \cdot 51)$ vs $2 \cdot 46(1 \cdot 36-3 \cdot 07))$.

To delineate antibody-binding regions of these TRAB on the ectodomain of TSHR, flow cytometry experiments were repeated for all sera with the TLT lines generated. The prevalence of sera positive on TLT cells was $90 \%$ with wild-type TSHR, $60 \%$ with S281N TSHR, $40 \%$ with I486F TSHR, and $70 \%$ with D633H TSHR groups. Overall, stratification of sera based on established cut-off levels showed concordance between the GT14 and TLT data $(P<0 \cdot 0001)$. 

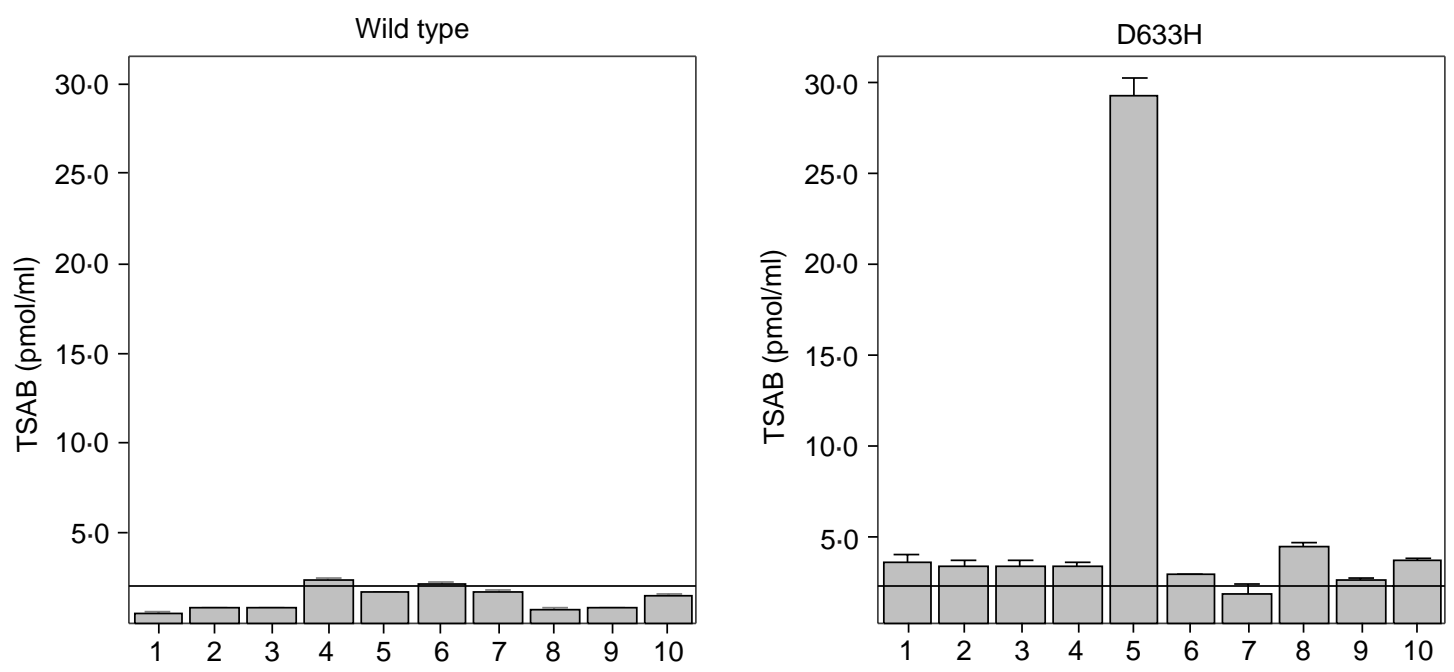

\begin{tabular}{|l|c|c|c|c|c|c|c|c|c|c|}
\hline GT14 & - & + & + & + & + & + & + & - & + & + \\
\hline JP19 & - & + & + & + & + & + & + & - & + & + \\
\hline
\end{tabular}

\begin{tabular}{|l|c|c|c|c|c|c|c|c|c|c|}
\hline GT14 & + & + & + & + & + & + & + & + & + & - \\
\hline JP19 & - & - & - & + & - & - & - & + & - & - \\
\hline
\end{tabular}
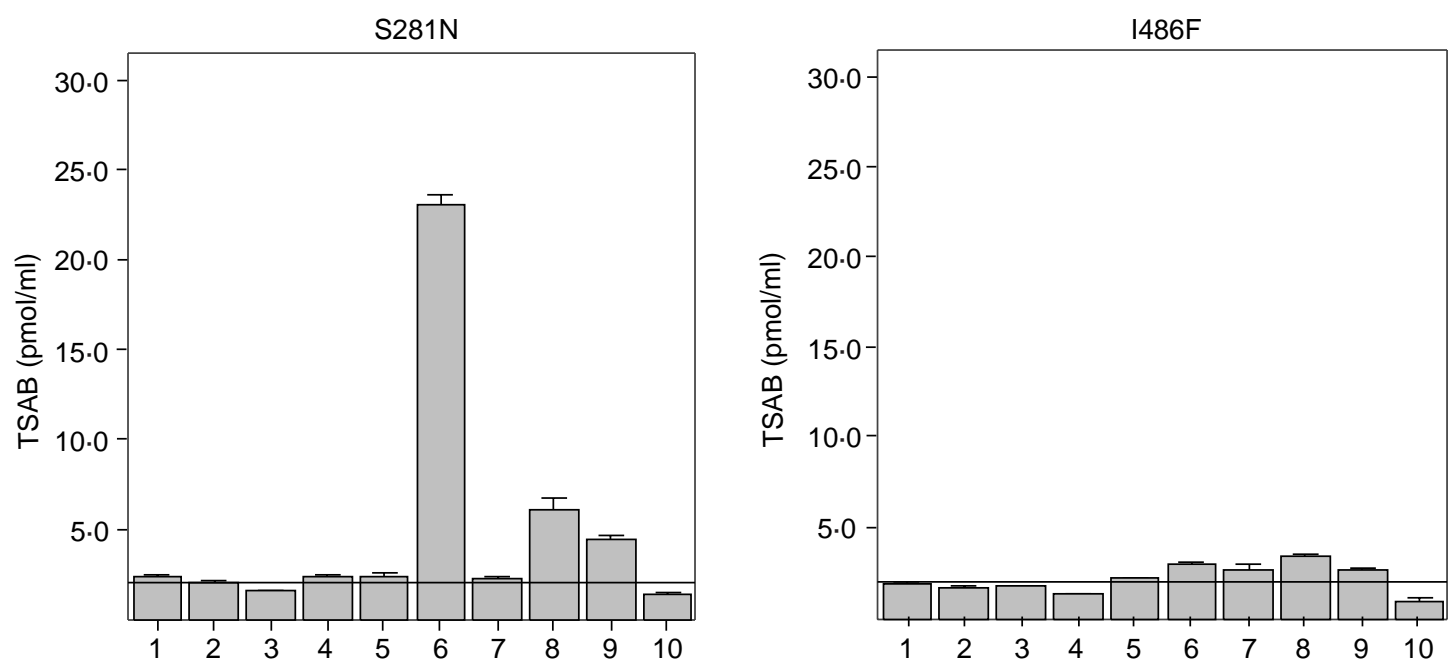

\begin{tabular}{|l|l|l|l|l|l|l|l|l|l|l|}
\hline GT14 & - & - & - & + & - & + & - & + & + & + \\
\hline JP19 & - & - & - & + & - & + & - & - & - & + \\
\hline
\end{tabular}

\begin{tabular}{|l|l|l|l|l|l|l|l|l|l|l|}
\hline GT14 & - & + & + & - & - & + & - & - & + & - \\
\hline JP19 & - & - & - & - & - & + & - & - & - & - \\
\hline
\end{tabular}

Figure 2 TSAB activities of Swiss outbred mice immunized with wild-type, S281N, I486F, and D633H TSHRs. Each serum was assayed in triplicate. Bars represent mean of triplicate results and error bars represent S.E. of mean. Solid grid line represents cut-off for TSAB assay set at $2 \cdot 14 \mathrm{pmol} / \mathrm{l}$. Mean values above this cut-off are considered positive for the assay. Immunization with wild-type TSHR generated only $20 \%$ positive sera, while S281N, I486F, and D633H TSHR groups had 80,50 , and $90 \%$ positive cases respectively. Increased prevalence in $\mathrm{S} 281 \mathrm{~N}$ and D633H TSHR groups was found to be significant $(P=0.023$ and 0.005 respectively). Injection with three activating mutants generated higher TSAB levels compared with wild-type receptor (wild type: 1.25 pmol/l (0.88-1.92) vs S281N: $2.50 \mathrm{pmol} / \mathrm{I}(2.06-5.00), P=0.005$; I486F: $2.15 \mathrm{pmol} / \mathrm{l}(1.72-2.90), P=0.013$; D633H: $3.28 \mathrm{pmol} / \mathrm{l}(2 \cdot 67-3 \cdot 76), P=0.001)$. Note that two mice achieved extremely high TSAB levels: mouse 6 in S281N TSHR group and mouse 5 in D633H TSHR group. Tables below bar charts show individual serum's flow cytometry status performed with GT14 and JP19 cell lines: + and - denote positive and negative results respectively. TSAB values did not correlate with flow cytometric readings on GT14 or JP19 cells.

The two flow cytometry readings also showed a high degree of correlation $(r=0 \cdot 81, P<0 \cdot 0001)$. TLT readings showed correlation with TBII levels $(r=0 \cdot 73$, $P<0.0001)$ but not with TSAB or TSBAB activities.
These findings suggest that regardless of functional profile, most of the TRAB found in both wild-type and mutant TSHR immunized mice bind to regions in the first 271 amino acid segment of the TSHR. 

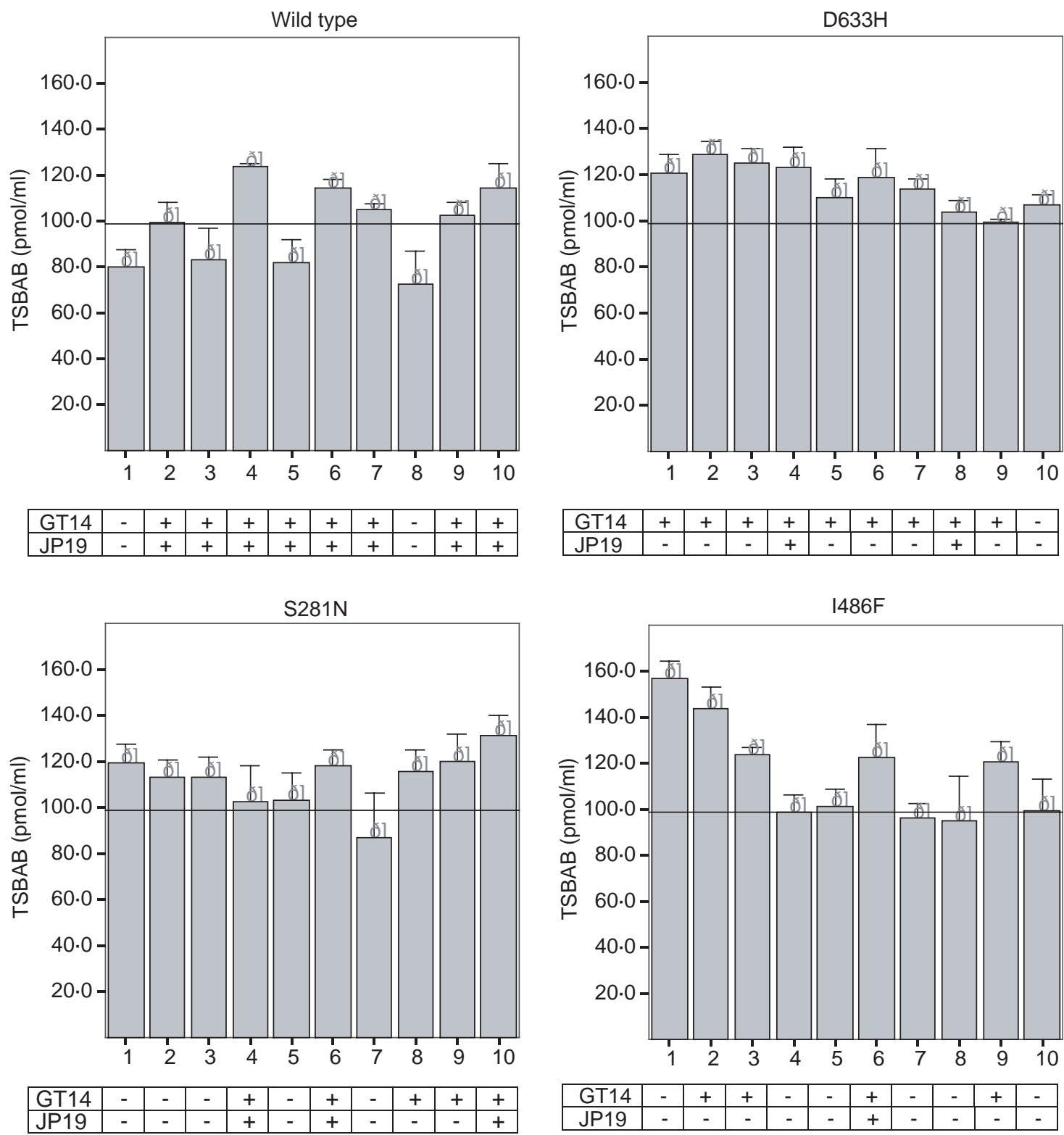

\begin{tabular}{|l|c|c|c|c|c|c|c|c|c|c|}
\hline GT14 & + & + & + & + & + & + & + & + & + & - \\
\hline JP19 & - & - & - & + & - & - & - & + & - & - \\
\hline
\end{tabular}

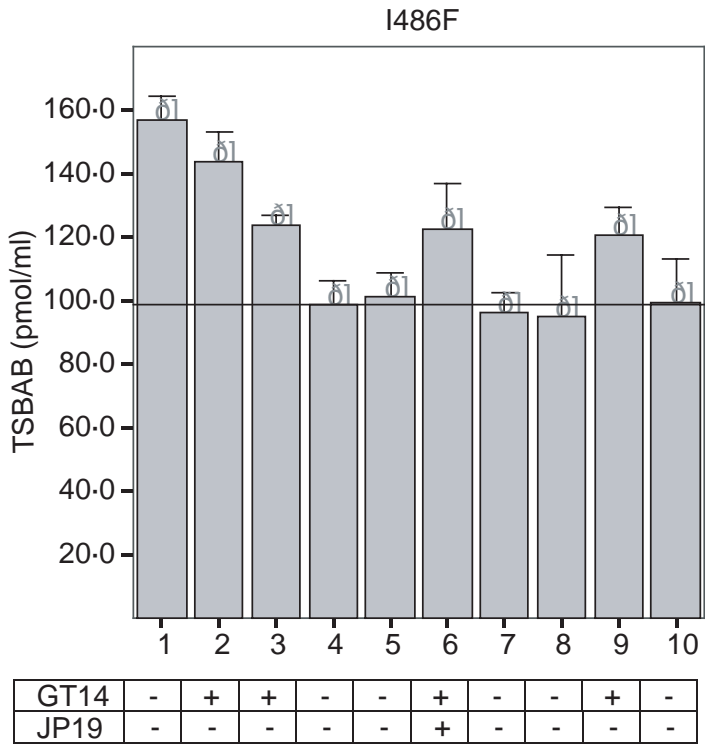

Figure 3 TSBAB activities of Swiss outbred mice immunized with wild-type, S281N, I486F, and D633H TSHRs. Each serum was assayed in triplicate. Bars represent mean of triplicate results and error bars represent S.E. of mean. Solid grid line represents cut-off for TSBAB assay set at $98.8 \mathrm{pmol} / \mathrm{ml}$. Mean values below this cut-off are considered positive for the assay. Immunization with wild-type TSHR generated $50 \%$ positive sera, while S281N and I486F TSHR groups had 10 and $30 \%$ positive cases respectively (results not statistically significant compared with wild-type TSHR group). D633H TSHR group sera were all negative for TSBAB and this absence was significant compared with wild-type group $(P=0.033)$. Median TSBAB levels in mutant receptor groups did not differ from wild-type group. However, among the TSBAB-positive sera, the majority obtained from wild-type receptor vaccination showed clear suppression of TSH-mediated CAMP production, while those obtained from mutant injections tended to be only marginally positive. Tables below bar charts show individual serum's flow cytometry status performed with GT14 and JP19 cell lines: + and - denote positive and negative results respectively. TSBAB values did not correlate with flow cytometric readings on GT14 or JP19 cells.

\section{Correlation of various TRAB measurements}

TBII was significantly correlated with TSBAB activity $(r=-0 \cdot 314, P=0 \cdot 026)$, a finding that was not surprising because measurement of TSBAB activity entails the displacement of ligand TSH. TBII, in addition, was also significantly correlated with FU readings obtained with JP19 cells $(r=0 \cdot 57, P<0 \cdot 001)$ and GT14 cells $(r=0 \cdot 74$, $P<0 \cdot 001)$. Although there was increased recognition by sera from mice immunized with mutant TSHRs for 

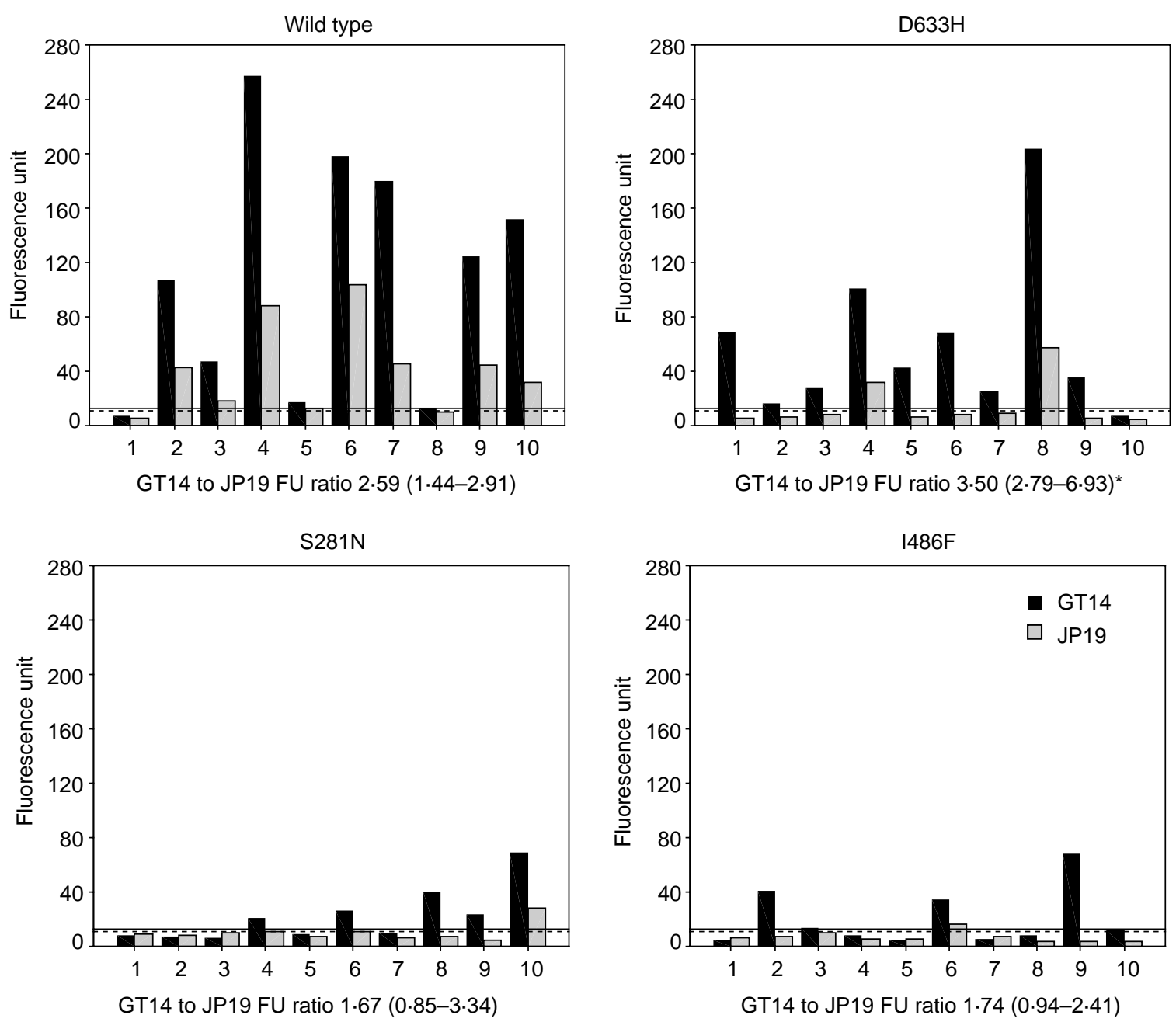

Figure 4 Flow cytometric readings obtained with each individual serum from GT14 ( $\square$ ) and JP19 ( $\square$ ) cells. Solid and dotted horizontal lines indicate cut-off values for GT14 and JP19 cell lines respectively, set at 2 S.D. from the mean of control group (13.1 FU for GT14 and 10.7 FU for JP19). In wild-type TSHR injected mice, results of GT14 and JP19 cells were concordant and showed high rate of prevalence $(80 \%)$. Sera from mice immunized with mutant receptors recognized JP cells poorly: $30 \%$ in S281N (result not significantly different from wild-type group), $10 \%$ in $1486 \mathrm{~F}$ ( $P=0.005$ compared with wild-type group), and $20 \%$ in $\mathrm{D} 633 \mathrm{H}(P=0.023$ compared with wild-type group) TSHR groups. Usage of GT14 cells reversed this situation and increased detection rate to 50,40 , and $90 \%$ respectively. *Fluorescence unit ratios of GT14 to JP19 cells were examined and found to be significantly higher in D633H TSHR group compared with wild-type receptor.

GT14 compared with JP19 cells, and of these mice often possessed stimulating antibodies, the correlation of TSAB with GT14 flow cytometric readings was not significant.

\section{Description of the three mice with elevated total T4 levels}

Only three mice showed elevated total $\mathrm{T} 4$ and they came from the groups immunized with wild-type (mouse number 10), I486F (mouse number 9), and D633H (mouse number 8 ) TSHRs. Their total T4 levels were $123 \cdot 4,113 \cdot 3$, and $144.9 \mathrm{nmol} / 1$ respectively (cut-off: $107.2 \mathrm{nmol} / \mathrm{l}$ ). These mice did not exhibit the highest level of TSAB in each of their respective cohorts. In fact, TSAB was negative in the thyrotoxic mouse (number 10) immunized with wild-type receptor (TSAB $1.55 \mathrm{pmol} / \mathrm{ml}$, cut-off: $2 \cdot 14 \mathrm{pmol} / \mathrm{ml}$ ). It was also negative for TSBAB but showed $60 \%$ displacement of radiolabeled bTSH on TBII assay. The thyrotoxic mouse immunized with I486F TSHR showed the highest FU with GT14 cells but its sera was blind to JP19 cells. It yielded a cAMP of $2 \cdot 80 \mathrm{pmol} / \mathrm{ml}$ on TSAB assay, fourth in rank amongst its cohort (maximum TSAB in group: $3.53 \mathrm{pmol} / \mathrm{ml}$ ). It was negative for TSBAB and showed 9\% displacement of radiolabeled ligand. The most thyrotoxic mouse in the entire batch came from $\mathrm{D} 633 \mathrm{H}$ receptor vaccination. Its TRAB showed the highest FU for both GT14 and JP19 cells 
in its own cohort. It also had the greatest TBII activity with $75 \%$ displacement of radiolabeled ligand. It was negative for TSBAB and generated $4.33 \mathrm{pmol} / \mathrm{ml} \mathrm{cAMP}$ on TSAB assay, second in rank in its cohort where the maximum cAMP produced was $29 \cdot 4 \mathrm{pmol} / \mathrm{ml}$.

\section{Description of two mice with the highest TSAB levels}

Two mice stood out amongst the entire study in having extremely high TSAB activities (Fig. 2). They were mouse number 6 (S281N TSHR group) and mouse number 5 (D633H TSHR group). They generated cAMP of 23.2 and $29.4 \mathrm{pmol} / \mathrm{ml}$ respectively, which represented 17- and 22-fold increases above the median of control group. Although positive for potent TSAB, neither were thyrotoxic. Number 6 had a T4 level of $90 \cdot 8 \mathrm{nmol} / 1$. Number 5 had the lowest T4 level of the 45 animals, $33.7 \mathrm{nmol} / 1$, which fell just short of the cut-off for hypothyroidism set at $32 \cdot 8 \mathrm{nmol} / 1$. Number 6 displaced $36 \%$ and number 5 displaced $6 \%$ of TSH in TBII assays. Both the mice were negative for TSBAB and their sera showed preferential recognition of GT14 cells over JP19 cells (Fig. 4).

\section{Discussion}

Genetic immunization with human TSHR cDNA is an effective means of generating TRAB although the rate of hyperthyroidism is generally low in mice. Vaccination of female $\mathrm{BALB} / \mathrm{c}$ mice produced predominantly TSBAB-positive antibodies with only $7 \cdot 1 \%$ ( 1 out of 14) mice showing TSAB activity. All animals had normal thyroid hormones (Costagliola et al. 1998a). Results in female NMRI outbred mice were better with $17 \cdot 2 \%$ (5 out of 29) mice positive for TSAB. The mice also showed T4 elevation and TSH suppression (Costagliola et al. 2000). Our study in Swiss outbred mice resulted in a lower induction rate with this protocol $(7 \cdot 5 \%$ (3 out of $40)$ ), contributed by additional factors such as genetic makeup of mouse strains and environmental differences between animal laboratories (Ludgate 2000). However, TRAB were commonly detected using various assays, demonstrating the dissociation between thyroid status and immunological responses against the antigen. Indeed, thyrotoxic mice were not the strongest producers of TSAB and neither did mice with high TSAB activities develop thyrotoxicosis. The discrepancies between T4 and TSAB, and in some studies thyroid histology, had been observed in both inbred and outbred mice (Yamada et al. 2002, Rao et al. 2003, Chen et al. 2004). Although dominance of TSBAB over TSAB and different serum dilution requirements for bioassays have been proposed as possible explanations (Chen et al. 2004), our TSAB-positive euthyroid animals lacked blocking antibodies and thus could not account for the findings. Another possibility is the production of TRAB with epitopes unique to human antigen, especially with the usage of mutated TSHRs, which interacts only with assays using human recombinant TSHR without generating any biological action on the mouse thyroid. Performing the TSAB assay using murine TSHR could potentially circumvent this shortcoming.

Murine GD models have been optimized by varying immunization methods and/or murine strains, with most studies using wild-type human TSHR or TSHR variants (Shimojo et al. 1996, Costagliola et al. 1998a, 2000, Kaithamana et al. 1999, Nagayama et al. 2002, Nagayama 2005). Vaccination with free A subunit instead of the full-length holoreceptor by adenovirus induced high rates of hyperthyroidism (Chen et al. 2003). Loss-of-function silencing mutation at codon $601(\mathrm{Y} 601 \mathrm{H})$ did not influence DNA vaccination outcome in BALB/c mice (Pichurin et al. 2002). The reverse strategy, i.e. immunization with activating TSHR mutants, was explored in this study, which compared their serological profiles with wild-type receptor vaccination. The three mutations, located in the ectodomain, exoloop, and transmembrane segments, each results in structure alteration and the adoption of active conformation important in receptor activation. The authors hypothesized that immunization with such mutants containing key amino acid changes may affect endosomal processing into peptides thereby exposing novel epitopes that are otherwise absent in wild-type receptor. This could be potentially important in generating an antibody repertoire critical for receptor activation. Indeed, findings from this study support this hypothesis. Vaccination with gain-of-function mutant TSHRs increased the prevalence of TSAB-positive sera and their median cAMP production when compared with injection with wild-type receptor. It also consistently generated a greater number of stimulating sera compared with blocking sera, while immunization with wild-type TSHR tended to produce more blockers than stimulators. Induction of TSAB was unrelated to the degree of gain-of-function (in descending order: I486F, $\mathrm{S} 281 \mathrm{~N}$, and $\mathrm{D} 633 \mathrm{H}$ (Ho et al. 2005)) since the weakest mutant D633H TSHR generated the highest prevalence of stimulating TRAB. Good cell-surface expression of D633H mutant (surface expression in descending order: D633H, S281, and I486F; Ho et al. 2005) or properties intrinsic to its conformational change might have contributed. Nevertheless, it is interesting that a mutation located in a domain not exposed on the cell surface could significantly influence immunization results. This is in contrast to the negative findings of Y601H loss-of-function mutant (Pichurin et al. 2002).

Besides functional differences, TRAB obtained from wild-type and mutant immunization also differed in their binding to ECD-GPI moiety and full-length 
holoreceptor on flow cytometry. In human, detection of TRAB binding to TSHR by flow cytometry was rarely achieved with full-length holoreceptors until the generation of ECD-GPI as a membrane protein (Costagliola et al. 1998b, Da Costa \& Johnstone 1998). TRAB present in GD sera also preferentially bound ECD-GPI over holoreceptor and ECD-GPI cytometry readings significantly correlated with TSAB activity. In contrast, TSBAB sera from hypothyroid patients recognized both ECD-GPI and full-length receptors equally well (Chazenbalk et al. 2002). Our mouse data shared many similarities. TRAB obtained from wildtype group often contained TSH-blocking activity and showed full concordance of JP19 and GT14 cytometric readout. Calculation of GT14 to JP19 FU ratios also showed that TBII- and TSBAB-positive sera significantly bound holoreceptor to a greater extent. In contrast, antibodies obtained from mice immunized with activating mutants often had TSAB bioactivities and preferentially recognized GT14 over JP19 cells, although the correlation between TSAB and GT14 flow cytometry data was negative. Discrepant binding to these two TSHR species has been attributed to steric hindrance found in holoreceptor to TSAB binding, which comes from the plasma membrane, the extracellular loops, or receptor multimerization (Chazenbalk et al. 2002). The ECD-GPI may thus be more accessible to antibody binding due to the greater flexibility offered by its anchor and the absence of receptor multimerization (Chen et al. 2001, Chazenbalk et al. 2002). Conversely, activating mutations at key residues could potentially convert the receptor into open conformations by the release of negative constraint exerted by the ectodomain acting as an inverse agonist on the transmembrane domain, thereby exposing crucial epitopes otherwise hidden in holoreceptor (Zhang et al. 2000, Vlaeminck-Guillem et al. 2002). This situation is akin to vaccination with purified A subunit (Chazenbalk et al. 1999).

Findings obtained with TLT chimera indicated that most of the TRAB, be it TSAB or TSBAB, had their binding regions confined to the first 271 amino acids of the TSHR. This region contains nine leucine-rich repeats that form a succession of $\beta$-strands and $\alpha$-helices organized into a horseshoe-shaped structure with which TSH and autoantibodies interact (Szkudlinski et al. 2002, Smits et al. 2003). Our data corroborate with findings that stimulating antibodies from GD patients and TSH-blocking antibodies from autoimmune hypothyroidism patients can both be neutralized by purified TSHR A subunits (Chazenbalk et al. 2002). TSH-blocking antibodies have, in addition, epitopes located on the holoreceptor. Thus, the previous concept that the epitopes for blocking antibodies are largely confined to the C-terminus of the ectodomain is oversimplified. Our findings are more in keeping with recent TRAB epitope studies, which indicate that binding sites for stimulating and blocking autoantibodies lie close together, not on distinct or distant parts of the TSHR molecule (Morgenthaler et al. 2003, Ando et al. 2004, Costagliola et al. 2004, Sanders et al. 2004, 2005, Schott et al. 2005).

\section{Conclusions}

Genetic immunization of Swiss outbred mice in our laboratory using either wild-type or constitutive activating mutant TSHRs was not as efficient in producing mouse thyrotoxicosis as previously reported (Costagliola et al. 2000). However, it was effective in generating TRAB, which was detected by methods utilizing human recombinant TSHR. Moreover, immunization with active receptor conformations, especially with $\mathrm{D} 633 \mathrm{H}$ mutant, generated higher prevalence of stimulating sera with higher median TSAB levels. In contrast, vaccination with receptor under basal state of activity in a constrained conformation would appear to preferentially generate blocking sera. It will be of interest to investigate the outcome of this strategy when applied to the other immunization methods. Regardless of functional activity, these autoantibodies could displace $\mathrm{TSH}$, and their epitopes were mapped to the first 271 amino acids of the TSHR, a region where the leucine-rich repeat region resides and interacts with TSH and TRAB. Therefore, this study corroborates findings that both stimulating and blocking antibodies overlap in their binding sites and are not exclusively located at the N- and C-termini of the receptor as previously suggested (Tahara et al. 1997, Kohn \& Harii 2003). Potentially, this study opens a novel approach in generating a spectrum of stimulating antibodies for the better understanding of receptor activation, a process that entails generation of monoclonal antibodies and definition of their epitopes.

\section{Acknowledgements}

The authors are grateful to (1) B R A H M S for the supply of radiolabeled TSH and (2) Drs G Vassart and S Costagliola for their kind gifts of mouse monoclonal antibodies, JP19, and GT14 cell lines used in this study.

\section{Funding}

National Medical Research Council of Singapore. Grant number: NMRC/0756/2003. There is no conflict of interest that would prejudice the study's impartiality. 


\section{References}

Ando T, Latif R, Daniel S, Eguchi K \& Davies TF 2004 Dissecting linear and conformational epitopes on the native thyrotropin receptor. Endocrinology 145 5185-5193.

Camacho P, Gordon D, Chiefari E, Yong S, DeJong S, Pitale S, Russo D \& Filetti S 2000 A Phe 486 thyrotropin receptor mutation in an autonomously functioning follicular carcinoma that was causing hyperthyroidism. Thyroid 10 1009-1012.

Chazenbalk GD, Wang Y, Guo J, Hutchison JS, Segal D, Jaume JC, McLachlan SM \& Rapoport B 1999 A mouse monoclonal antibody to a thyrotropin receptor ectodomain variant provides insight into the exquisite antigenic conformational requirement, epitopes and in vivo concentration of human autoantibodies. Journal of Clinical Endocrinology and Metabolism 84 702-710.

Chazenbalk GD, Pichurin P, Chen CR, Latrofa F, Johnstone AP, McLachlan SM \& Rapoport B 2002 Thyroid-stimulating autoantibodies in Graves' disease preferentially recognize the free A subunit, not the thyrotropin holoreceptor. Journal of Clinical Investigation 110 209-217.

Chen CR, Tanaka K, Chazenbalk GD, McLachlan SM \& Rapoport B 2001 A full biological response to autoantibodies in Graves' disease requires a disulfide-bonded loop in the thyrotropin receptor $\mathrm{N}$ terminus homologous to a laminin epidermal growth factor-like domain. Journal of Biological Chemistry 276 14767-14772.

Chen CR, Pichurin P, Nagayama Y, Latrofa F, Rapoport B \& McLachlan SM 2003 The thyrotropin receptor autoantigen in Graves' disease is the culprit as well as the victim. Journal of Clinical Investigation 111 1897-1904.

Chen CR, Aliesky H, Pichurin PN, Nagayama Y, McLachlan SM \& Rapoport B 2004 Susceptibility rather than resistance to hyperthyroidism is dominant in a thyrotropin receptor adenovirusinduced animal model of Graves' disease as revealed by BALB/cC57BL/6 hybrid mice. Endocrinology 145 4927-4933.

Costagliola S, Rodien P, Many MC, Ludgate M \& Vassart G 1998 a Genetic immunization against the human thyrotropin receptor causes thyroiditis and allows production of monoclonal antibodies recognizing the native receptor. Journal of Immunology $1601458-1465$.

Costagliola S, Khoo D \& Vassart G $1998 b$ Production of bioactive amino-terminal domain of the thyrotropin receptor via insertion in the plasma membrane by a glycosylphosphatidylinositol anchor. FEBS Letter 436 427-433.

Costagliola S, Many MC, Denef JF, Pohlenz J, Refetoff S \& Vassart G 2000 Genetic immunization of outbred mice with thyrotropin receptor cDNA provides a model of Graves' disease. Journal of Clinical Investigation 105 803-811.

Costagliola S, Franssen JD, Bonomi M, Urizar E, Willnich M, Bergmann A \& Vassart G $2002 a$ Generation of a mouse monoclonal TSH receptor antibody with stimulating activity. Biochemical and Biophysical Research Communications 299 891-896.

Costagliola S, Panneels V, Bonomi M, Koch J, Many MC, Smits G \& Vassart G $2002 b$ Tyrosine sulfation is required for agonist recognition by glycoprotein hormone receptors. EMBO Journal 21 504-513.

Costagliola S, Bonomi M, Morgenthaler NG, Van Durme J, Panneels V, Refetoff S \& Vassart G 2004 Delineation of the discontinuousconformational epitope of a monoclonal antibody displaying full in vitro and in vivo thyrotropin activity. Molecular Endocrinology 18 3020-3034.

Da Costa CR \& Johnstone AP 1998 Production of the thyrotrophin receptor extracellular domain as a glycosylphosphatidylinositolanchored membrane protein and its interaction with thyrotrophin and autoantibodies. Journal of Biological Chemistry 273 11874-11880.

Davies TF, Ando T, Lin RY, Tomer Y \& Latif R 2005 Thyrotropin receptor-associated diseases: from adenomata to Graves' disease. Journal of Clinical Investigation 115 1972-1983.
Duprez L, Parma J, Costagliola S, Hermans J, Van Sande J, Dumont JE \& Vassart G 1997 Constitutive activation of the TSH receptor by spontaneous mutations affecting the N-terminal extracellular domain. FEBS Letter 409 469-474.

Gruters A, Schoneberg T, Biebermann H, Krude H, Krohn HP, Dralle H \& Gudermann T 1998 Severe congenital hyperthyroidism caused by a germ-line neo mutation in the extracellular portion of the thyrotropin receptor. Journal of Clinical Endocrinology and Metabolism 83 1431-1436.

Ho SC, Van Sande J, Lefort A, Vassart G \& Costagliola S 2001 Effects of mutations involving the highly conserved S281HCC motif in the extracellular domain of the thyrotropin (TSH) receptor on TSH binding and constitutive activity. Endocrinology 142 2760-2767.

Ho SC, Goh SS, Su Q \& Khoo DH 2005 Cysteine 390 mutation of the TSH receptor modulates its ectodomain as an inverse agonist on the serpentine domain with decrease in basal constitutive activity. Molecular and Cellular Endocrinology 21 158-168.

Kaithamana S, Fan J, Osuga Y, Liang SG \& Prabhakar BS 1999 Induction of experimental autoimmune Graves' disease in $B A L B / \mathrm{c}$ mice. Journal of Immunology 163 5157-5164.

Kohn LD \& Harii N 2003 Thyrotropin receptor autoantibodies (TSHRAbs): epitopes, origins and clinical significance. Autoimmunity 36 331-337.

Kopp P, Muirhead S, Jourdain N, Gu WX, Jameson JL \& Rodd C 1997 Congenital hyperthyroidism caused by a solitary toxic adenoma harboring a novel somatic mutation (serine281-> isoleucine) in the extracellular domain of the thyrotropin receptor. Journal of Clinical Investigation 100 1634-1639.

Ludgate M 2000 Animal models of Graves' disease. European Journal of Endocrinology 142 1-8.

Ludgate M, Costagliola S, Danguy D, Perret J \& Vassart G 1992 Recombinant TSH-receptor for determination of TSH-receptorantibodies. Experimental and Clinical Endocrinology 100 73-74.

Morgenthaler NG, Minich WB, Willnich M, Bogusch T, Hollidt JM, Weglohner W, Lenzner C \& Bergmann A 2003 Affinity purification and diagnostic use of TSH receptor autoantibodies from human serum. Molecular and Cellular Endocrinology 212 73-79.

Nagayama Y 2005 Animal models of Graves' hyperthyroidism. Endocrine Journal 52 385-394.

Nagayama Y, Kita-Furuyama M, Ando T, Nakao K, Mizuguchi H, Hayakawa T, Eguchi K\& Niwa M 2002 A novel murine model of Graves' hyperthyroidism with intramuscular injection of adenovirus expressing the thyrotropin receptor. Journal of Immunology 168 2789-2794.

Parma J, Van Sande J, Swillens S, Tonacchera M, Dumont J \& Vassart G 1995 Somatic mutations causing constitutive activity of the thyrotropin receptor are the major cause of hyperfunctioning thyroid adenomas: identification of additional mutations activating both the cyclic adenosine $3^{\prime}, 5^{\prime}$-monophosphate and inositol phosphate-Ca ${ }^{2+}$ cascades. Molecular Endocrinology 9 725-733.

Parma J, Duprez L, Van Sande J, Hermans J, Rocmans P, Van Vliet G, Costagliola S, Rodien P, Dumont JE \& Vassart G 1997 Diversity and prevalence of somatic mutations in the thyrotropin receptor and Gs alpha genes as a cause of toxic thyroid adenomas. Journal of Clinical Endocrinology and Metabolism 82 2695-2701.

Pichurin B, Pichurina SM, Chazenbalk GD, Paras C, Chen CR, Rapoport B \& McLachlan SM 2002 Immune deviation away from Th1 in interferon-gamma knockout mice does not enhance TSH receptor antibody production after naked DNA vaccination. Endocrinology 143 1182-1189.

Rao PV, Watson PF, Weetman AP, Carayanniotis G \& Banga JP 2003 Contrasting activities of thyrotropin receptor antibodies in experimental models of Graves' disease induced by injection of transfected fibroblasts or deoxyribonucleic acid vaccination. Endocrinology 144 260-266.

Russo D, Arturi F, Suarez HG, Schlumberger M, Du Villard JA, Crocetti U \& Filetti S 1996 Thyrotropin receptor gene alterations in thyroid hyperfunctioning adenomas. Journal of Clinical Endocrinology and Metabolism 81 1548-1551. 
Russo D, Tumino S, Arturi F, Vigneri P, Grasso G, Pontecorvi A, Filetti S \& Belfiore A 1997 Detection of an activating mutation of the thyrotropin receptor in a case of an autonomously hyperfunctioning thyroid insular carcinoma. Journal of Clinical Endocrinology and Metabolism 82 735-738.

Sanders J, Jeffreys J, Depraetere H, Evans M, Richards T, Kiddie A, Brereton K, Premawardhana LD, Chirgadze DY, Nunez Miguel R et al. 2004 Characteristics of a human monoclonal autoantibody to the thyrotropin receptor: sequence structure and function. Thyroid 14 560-570.

Sanders J, Allen F, Jeffreys J, Bolton J, Richards T, Depraetere H, Nakatake N, Evans M, Kiddie A, Premawardhana LD et al. 2005 Characteristics of a monoclonal antibody to the thyrotropin receptor that acts as a powerful thyroid-stimulating autoantibody antagonist. Thyroid 15 672-682.

Schott M, Scherbaum WA \& Morgenthaler NG 2005 Thyrotropin receptor autoantibodies in Graves' disease. Trends in Endocrinology and Metabolism 16 243-248.

Shimojo N, Kohno Y, Yamaguchi K, Kikuoka S, Hoshioka A, Niimi H, Hirai A, Tamura Y, Saito Y, Kohn LD et al. 1996 Induction of Graves'-like disease in mice by immunization with fibroblasts transfected with the thyrotropin receptor and a class II molecule. PNAS 93 11074-11079.

Smits G, Campillo M, Govaerts C, Janssens V, Richter C, Vassart G, Pardo L \& Costagliola S 2003 Glycoprotein hormone receptors: determinants in leucine-rich repeats responsible for ligand specificity. EMBO Journal 22 2692-2703.

Szkudlinski MW, Fremont V, Ronin C \& Weintraub BD 2002 Thyroidstimulating hormone and thyroid-stimulating hormone receptor structure-function relationships. Physiological Reviews 82 473-502.
Tahara K, Ishikawa N, Yamamoto K, Hirai A, Ito K, Tamura Y, Yoshida S, Saito Y \& Kohn LD 1997 Epitopes for thyroid stimulating and blocking autoantibodies on the extracellular domain of the human thyrotropin receptor. Thyroid 7 867-877.

Tonacchera M, Vitti P, Agretti P, Giulianetti B, Mazzi B, Cavaliere R, Ceccarini G, Fiore E, Viacava P, Naccarato A et al. 1998 Activating thyrotropin receptor mutations in histologically heterogeneous hyperfunctioning nodules of multinodular goiter. Thyroid 8 559-564.

Vlaeminck-Guillem V, Ho SC, Rodien P, Vassart G \& Costagliola S 2002 Activation of the cAMP pathway by the TSH receptor involves switching of the ectodomain from a tethered inverse agonist to an agonist. Molecular Endocrinology 16 736-746.

Weetman AP 2000 Graves' disease. New England Journal of Medicine 343 1236-1248.

Yamada M, Li AW, West KA, Chang CH \& Wall JR 2002 Experimental model for ophthalmopathy in BALB/c and outbred (CD-1) mice genetically immunized with G2s and the thyrotropin receptor. Autoimmunity 35 403-413.

Zhang M, Tong KP, Fremont V, Chen J, Narayan P, Puett D, Weintraub BD \& Szkudlinski MW 2000 The extracellular domain suppresses constitutive activity of the transmembrane domain of the human TSH receptor: implications for hormone-receptor interaction and antagonist design. Endocrinology 141 3514-3517.

Received in final form 3 November 2006 Accepted 20 November 2006

Made available online as an Accepted Preprint 12 December 2006 